\title{
SISTEMA HÍBRIDO DE CARVÃO ATIVADO IMPREGNADO COM COMPOSTOS METÁLICOS E MEMBRANA
}

\author{
N. U. YAMAGUCHI ${ }^{1,2}$, S. A. L. ABE ${ }^{1}$, O. A. A. $\operatorname{SANTOS}^{1}$, F. S. ARAKAWA ${ }^{1}$, Q. L. \\ SHIMABUKU $^{1}$, F. J. BASSETTI ${ }^{4}$ A. M. S. VIEIRA ${ }^{3}$, R. BERGAMASCO ${ }^{1}$ \\ ${ }^{1}$ Universidade Estadual de Maringá, Departamento de Engenharia Química \\ ${ }^{2}$ Centro Universitário UniCesumar, Departamento de Engenharia \\ ${ }^{3}$ Universidade Estadual de Maringá, Departamento de Engenharia de Alimentos \\ ${ }^{4}$ Universidade Tecnológica Federal do Paraná, Departamento Acadêmico de Química e Biologia \\ E-mail para contato: nataliaueda@hotmail.com
}

\begin{abstract}
RESUMO - Neste trabalho foi avaliado um sistema gravitacional simples e econômico composto de carvão ativado associado à uma membrana polimérica comercial para melhoria da qualidade da água destinada ao consumo humano. O sistema de filtração era composto de membrana plana de acetato de celulose de $3 \mu \mathrm{m}$ de diâmetro de poro e carvão ativado granular. Com o objetivo de melhorar a eficiência bactericida foram impregnados compostos metálicos na superfície do carvão ativado com concentrações de $0,5 \%$ de cobre e $0,5 \%$ de prata. Também foram realizados ensaios para o processo unitário a fim de comparar com o processo híbrido. O sistema híbrido apresentou um aumento na remoção de cloro livre e maior fluxo permeado. Além disso, o carvão ativado impregnado com compostos metálicos apresentou uma melhoria na remoção de Escherichia coli, sendo superior a $99 \%$. O sistema estudado revelou ter alto potencial na melhoria da qualidade da água tratada, produzindo água de alta qualidade destinada ao consumo humano.
\end{abstract}

\section{INTRODUÇÃO}

O desenvolvimento de novas tecnologias para o tratamento e pós-tratamento de água destinada ao consumo humano tem sido uma necessidade crescente devido à conservação inadequada do solo e dos mananciais de onde a água é captada (Rebouças, 2004). Mesmo onde o tratamento convencional é empregado, avarias na tubulação, manutenção deficiente da rede e constantes quedas de pressão podem oferecer água de qualidade duvidosa para os consumidores em suas residências (Brick et al., 2004; Rebouças, 2004).

Os principais fatores de risco da água para consumo, principalmente em países em desenvolvimento, estão associados à contaminação microbiológica (Peter-Varbanets et al., 2009). A água pode disseminar doenças, atuando como um portador passivo de patógenos infecciosos, principalmente relacionados à contaminação fecal das fontes de água (Gadgil, 1998).

Com a finalidade de garantir que a água de consumo chegue ao consumidor final com qualidade assegurada nos casos onde o tratamento centralizado não é eficiente, sistemas de 


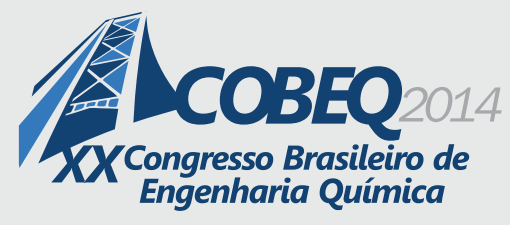

19 a 22 de outubro de 2014
Florianópolis/SC

tratamento de água descentralizados/domésticos simples têm sido utilizados para atuarem como uma barreira final para o consumidor (Peter-Verbanets, et al., 2009). Para estes sistemas podem ser utilizadas tecnologias não convencionais de tratamento, como por exemplo: radiação ultravioleta, ozônio, membranas microporosas, filtração em carvão ativado, zeólitas, resinas de troca iônica, entre outros, devido à eficácia destas tecnologias para remoção de diversos tipos de contaminantes.

O carvão ativado tem sido largamente utilizado no tratamento de água devido ao seu alto poder de adsorção, para controle de cor e odor, bem como para a remoção de compostos orgânicos, metais tóxicos e cloro (Hetrick et al., 2000). Porém, apesar de sua área superficial elevada, o carvão ativado tem baixa eficiência na remoção de microrganismos. A incorporação de metais na sua superfície tem sido utilizada por diversos autores (Miotto et al., 2000; Park e Jang, 2003; Zhao et al., 2012) para aumentar a eficiência bacteriológica para produção de filtros domésticos que garantam a qualidade da água potável para o consumidor final

Processos com membranas também pode ser uma forma alternativa para remoção de contaminantes presentes na água. Quando a água passa pelo filtro sob uma pressão transmembrana fornecida pela gravidade ou bomba, microorganismos e contaminantes particulados são removidos (Gao et al., 2011). Embora os processos com membranas tenham crescido rapidamente durante os últimos vinte anos, o problema de fouling da membrana é sempre uma questão critica que inibe a sua mais ampla aplicação para a produção de água potável (Gao et al., 2011).

Para melhorar o desempenho do tratamento, sistemas com membranas a baixas pressões têm sido acoplados com outros processos. Entre estes processos, adsorção por carvão ativado tem recebido atenção nas últimas duas décadas. A filtração por membranas a baixa pressão acoplados com carvão ativado tem sido uma solução emergente e promissora, chamada de processo híbrido com membrana (Stoquart et al., 2012).

Este trabalho utilizou um sistema de filtração híbrido gravitacional inovador composto de membrana polimérica comercial de acetato de celulose e carvão ativado impregnado com cobre e prata para a melhoria da qualidade da água destinada ao consumo humano. Além da avaliação dos sistemas híbridos, também foi avaliado o processo unitário, com a membrana sem carvão ativado, a fim de comparar os processos.

\section{MATERIAIS E MÉTODOS}

Para melhoria do desempenho do carvão ativado para redução microbiológica foi feita a impregnação de cobre e prata na superfície do carvão. Utilizou-se a técnica da impregnação úmida, com excesso de solução de nitrato de prata e sulfato de cobre nas concentrações de 0,5\% de cobre e 0,5\% de prata (Arakawa, 2011; Silva-Medeiros, 2012; Yamaguchi, 2013). Adicionouse GAC e água deionizada na proporção 1:1 (m/m) em balão de evaporador rotativo, e em seguida, sulfato de cobre e nitrato de prata em solução em quantidades suficientes para atingir a concentração desejada. Essa mistura permaneceu então sob agitação (20 rpm) e aquecimento 
$\left(60^{\circ} \mathrm{C}\right)$ por 24 horas. Depois desta etapa, o excesso de água foi retirado com pressão negativa à $80^{\circ} \mathrm{C}$ e a amostra foi levada para secagem em estufa à $100^{\circ} \mathrm{C}$ por 24 horas. Após a secagem, $\mathrm{o}$ carvão foi submetido ao tratamento térmico em forno mufla a uma temperatura de $350^{\circ} \mathrm{C}$ por 5 horas. A amostra foi submetida a uma lavagem a fim de remover os íons que não foram impregnados e o carvão pulverizado durante o tratamento térmico, seguida de uma última secagem em estufa a $100^{\circ} \mathrm{C}$.

Neste trabalho foram avaliados o processo unitário (membrana sem o pré-tratamento), o processo híbrido de membrana e carvão ativado, e o processo híbrido de membrana com o carvão ativado impregnado com metais. O módulo de filtração utilizado neste trabalho, desenvolvido por Bergamasco et al. (2011) e Silva et al. (2011) está apresentado na Figura 1.

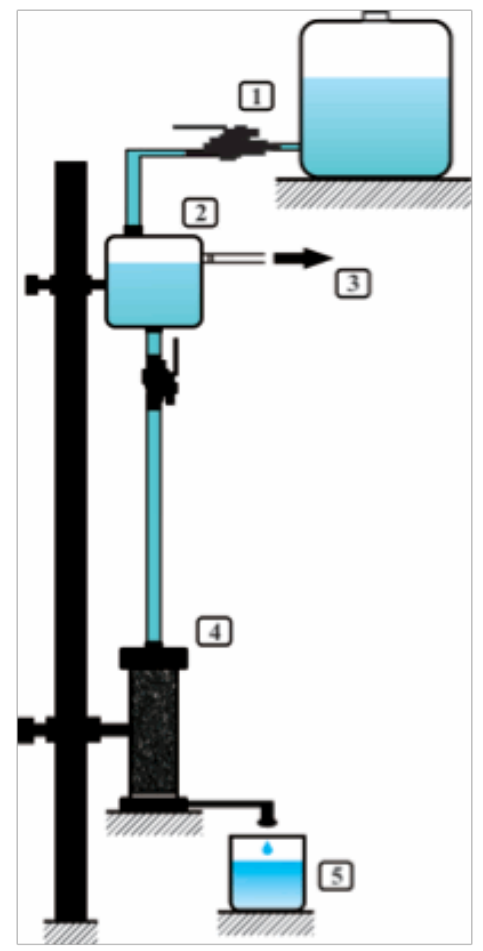

1) Tanque principal

2) Tanque de alimentação

3) Dreno

4) Módulo de filtração

5) Coleta de permeado

Figura 1 - Sistema de filtração gravitacional.

O sistema é composto por um tanque principal com capacidade de $20 \mathrm{~L}$ (1), que armazena a água a ser tratada e supre o tanque de alimentação (2). O dreno (3) mantém o nível de água constante no tanque de alimentação, com a finalidade de não alterar a altura da coluna d'água (3,1 metros), e conseqüentemente mantendo a pressão constante $(0,31$ bar, resultante da coluna d'água). As membranas planas eram colocadas na parte de baixo do módulo de filtração (4), conforme indicado na Figura 4.7 e 4.8. A superfície efetiva da membrana era de $1,962 \times 10^{-3} \mathrm{~m}^{2}$, e o permeado era coletado perpendicularmente à área da membrana (5), caracterizando uma operação de filtração perpendicular. 
Para avaliar o desempenho do filtro, foram feitos ensaios para remoção de cloro e de remoção bacteriológica:

Avaliação de remoção de cloro livre: O desempenho para remoção de cloro livre foi avaliado em ensaio separado da avaliação bacteriológica. Água de torneira foi filtrada e a remoção de cloro foi determinada através da quantidade de cloro presente antes (na água de torneira) e após a filtração (permeado). Estas medidas foram realizadas a cada $30 \mathrm{~min}$ de operação e o tempo total de operação foi de 8 horas.

Avaliação bacteriológica: A avaliação de remoção de Escherichia coli, foi utilizada água contaminada artificialmente com concentração entre $10^{5}$ e $10^{6}$ UFC/100 ml, e realizada de acordo com o descrito pela NBR 16098 (ABNT, 2012). Depois da filtração da água contaminada, a remoção de E. coli foi avaliada utilizando-se a técnica da membrana filtrante, conforme descrito no Standard Methods for the Examination for Water and Wastewater (APHA et al., 2012). Estes ensaios foram realizados no início e final da vida útil do filtro. A vida útil do filtro foi determinada pela passagem de água da torneira por um período de $8 \mathrm{~h}$ de operação.

\section{RESULTADOS E DISCUSSÃO}

\subsection{Avaliação de Remoção de Cloro Livre}

Os resultados obtidos para a eficiência de remoção de cloro encontram-se na Figura 2.

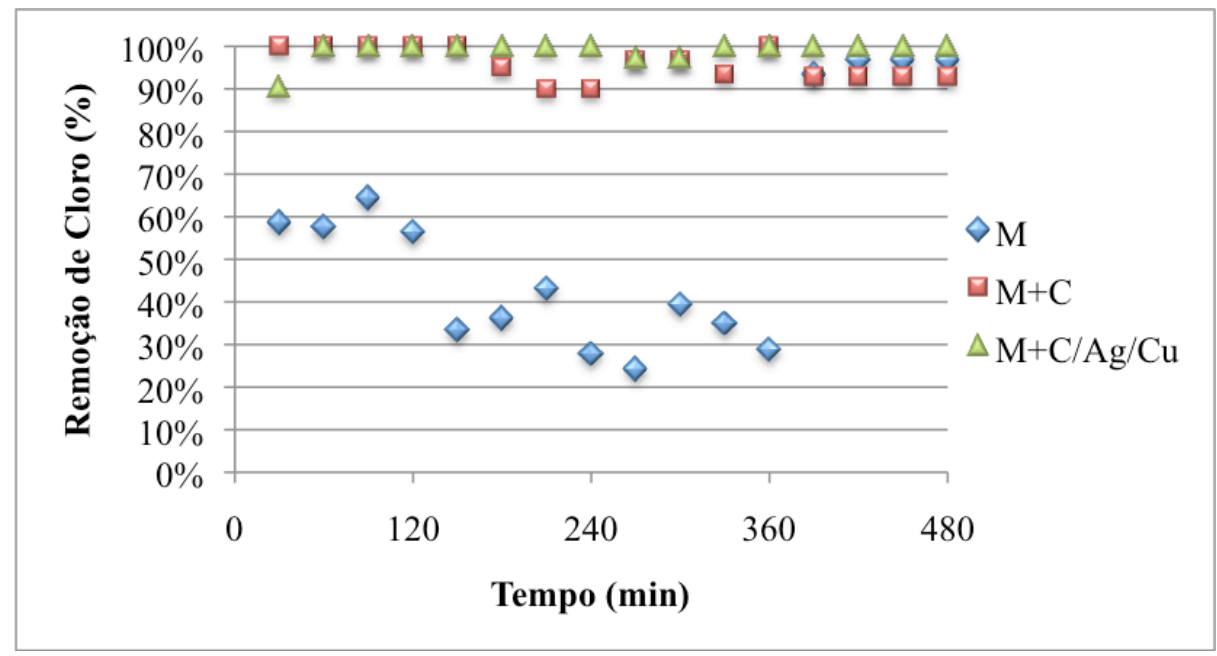

Figura 2 - Remoção de cloro para as diferentes configurações.

A remoção no sistema membrana variou entre $20-65 \%$, exceto no final da vida útil da membrana, que esta atingiu remoções maiores que $90 \%$ devido ao entupimento da membrana. Os sistemas híbridos apresentaram remoções acima de $90 \%$ durante todo o período de filtração. A 
remoção de cloro para os sistemas híbridos foi nitidamente maior do que no sistema unitário, indicando que o cloro é removido em maior parte pelo carvão ativado e não pela membrana.

\subsection{Avaliação Bactericida}

Os resultados obtidos para a eficiência bacteriológica encontram-se na Figura 3.

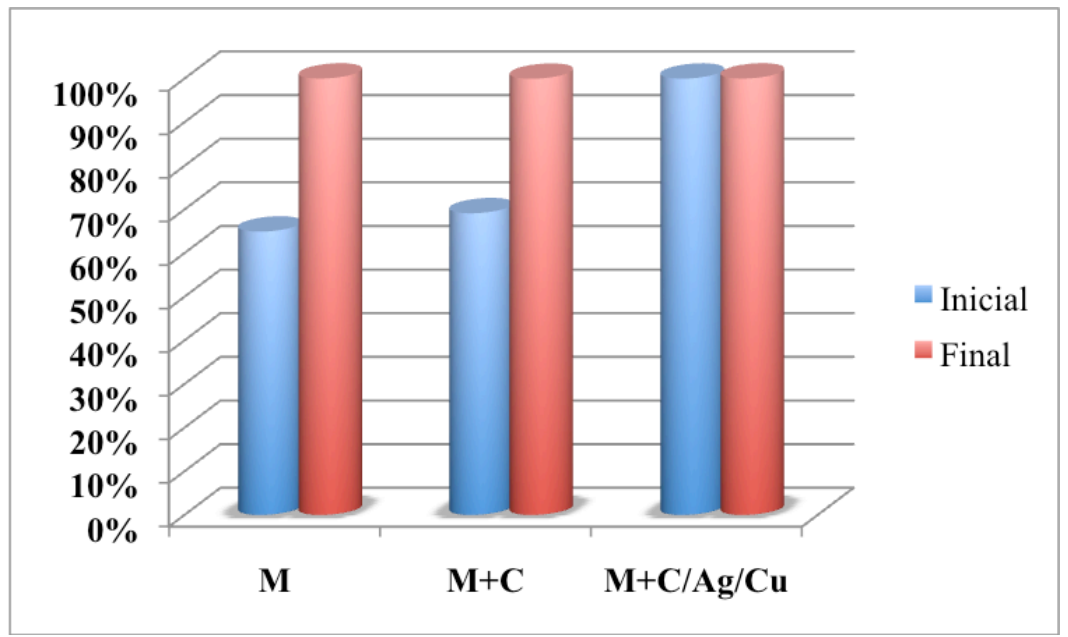

Figura 3 - Eficiência de remoção bacteriológica para as diferentes configurações.

Os três processos apresentaram menor remoção inicial em relação à remoção final. Isto é justificado pelo fato de que a membrana sem uso não apresenta os poros obstruídos, dessa forma, a $E$. coli pode atravessar os poros da membrana que estão desobstruídos. O processo híbrido com carvão impregnado com metais atingiu a remoção de 2 log exigida pela NBR 16098 (ABNT, 2012) no inicio e final da vida útil.

\section{CONCLUSÕES}

O processo com membrana e carvão ativado impregnado com metais apresentou resultados de acordo com o exigido pela a NBR 16098 (ABNT, 2012). Estes resultados revelaram que, a união das duas tecnologias, membrana polimérica e carvão ativado impregnado com metais, podem ser consideradas inovadoras na melhoria da qualidade da água potável destinada ao consumo humano em filtros gravitacionais descentralizados, pois apresentaram melhores remoções de cloro e bactérias, quando comparado com o processo unitário e quando comparado com o processo com membrana e carvão ativado sem impregnação de metais.

\section{AGRADECIMENTOS}

Os autores agradecem à Universidade Estadual de Maringá (UEM), ao Departamento de Engenharia Química (DEQ/UEM), ao Complexo de Centrais de Apoio à Pesquisa da 
Universidade Estadual de Maringá (COMCAP), ao apoio financeiro do Conselho Nacional de Desenvolvimento Científico e Tecnológico (CNPq) e à empresa Purific do Brasil Ltda.

\section{REFERÊNCIAS}

ABNT. NBR 16098 - Aparelho para melhoria da qualidade da água para uso doméstico. Aparelho por gravidade, anexo C. 2012.

APHA; AWWA ; WEF. Standard Methods for the examination of water and wastewater. Washington, D. C.: APHA, AWWA, WEF, 2012.

ARAKAWA, F. V. S. Módulos de filtração gravitacional com carvão ativado impregnado com ions metálicos para obtenção de água destinada ao consumo humano. 2011. 120 f. Dissertação (Mestre em Engenharia Química) - Departamento de Engenharia Química, Universidade Estadual Maringá, Maringá, 2011.

BERGAMASCO, R.; DA SILVA, F. V.; ARAKAWA, F. S.; YAMAGUCHI, N. U.; REIS, M. H. M.; TAVARES, C. J.; DE AMORIM, M. T. P. S. ; TAVARES, C. R. G. Drinking water treatment in a gravimetric flow system with $\mathrm{TiO} 2$ coated membranes. Chemical Engineering Journal, v. 174, p. 102-109, 2011.

BRICK, T.; PRIMROSE, B.; CHANDRASEKHAR, R.; ROY, S.; MULIYIL, J.; KANG, G. Water contamination in urban south India: household storage practices and their implications for water safety and enteric infections. International Journal of Hygiene and Environmental Health, v. 207, p. 473-480, 2004.

SILVA, F. V.; YAMAGUCHI, N. U.; LOVATO, G. A.; DA SILVA, F. A.; REIS, M. H. M.; DE AMORIM, M. T. P. S.; TAVARES, C. R. G. ; BERGAMASCO, R. Effects of coconut granular activated carbon pretreatment on membrane filtration in a gravitational driven process to improve drinking water quality. Environmental Technology, v. 33, p. 711-716, 2011.

GADGIL, A. Drinking water in developing countries. Annual Review of Energy and the Environment, v. 23, p. 253-286, 1998.

GAO, W.; LIANG, H.; MA, J.;HAN, M.; CHEN, Z. L., HAN Z. S.; LI, G. B. Membrane fouling control in ultrafiltration technology for drinking water production: A review. Desalination, v. 272, p. 1-8, 2011.

HETRICK, J.; PARKER, R.; PISIGAN, R.; THURMAN, N. Progress report on estimating pesticide concentrations in drinking water and assessing water treatment effects on pesticides removal and transformation: a consulation, Briefing document for a presentation to the FIFRA Scientific advisory panel. 2000.

MIOTTO, D.M.M., MACHADO, N.R.C.F., LIMA S.M., PEREIRA, N.C., PRADO FILHO, B.D., ABREU FILHO, B.A., 2000, "Estudo da eficiência de filtros de carvão ativo impregnados com prata”. In: XVII Simpósio Ibero-Americano de Catálise, Porto, Portugal, 16-21 Julho. 
PARK, S. J.; JANG, Y. S. Preparation and characterization of activated carbon fibers supported with silver metal for antibacterial behavior. Journal of Colloid and Interface Science, v. 261, p. 238-243, 2003.

PETER-VARBANETS, M.; ZURBRÜGG C.; SWARTZ, C.; PRONK, W. Decentralized systems for potable water and the potential of membrane technology. Water Research, v. 43, p. 245-265, 2009.

REBOUÇAS, A. Uso inteligente da água. São Paulo: Câmara Brasileira do Livro, Escrituras Editora, 2004.

SILVA-MEDEIROS, F. V. V. D. Desenvolvimento de Materiais Filtrantes a Partir da Modificação de Meios Porosos para a Melhoria da Qualidade da Água Destinada ao Consumo Humano. 2012. 186 f. Tese (Doutorado em Engenharia Química) - Departamento de Engenharia Química, Universidade Estadual de Maringá, Maringá, 2012.

STOQUART, C.; SERVAIS, P.; BÉRUBÉ, P. R.; BARBEAU, B. Hybrid Membrane Processes using activated carbon treatment for drinking water: A review. Journal of Membrane Science, v. 411-412, p. 1-12, 2012

YAMAGUCHI, N. U. Filtro híbrido de carvão ativado e membrana para purificação da água de consumo humano. 2013. 154 f. Dissertação (Mestre em engenharia química) - Departamento de Engenharia Química, Universidade Estadual de Maringá, Maringá, 2013.

ZHAO, Y.; WANG, Z. Q.; ZHAO, X.; LI, W.; LIU, S. X. Antibacterial action of silver-doped activated carbon prepared by vacuum impregnation. Applied Surface Science, article in press, 2012. 